\title{
ПАРАМЕТРИЧЕСКИЙ СИНТЕЗ МЕХАНИЗМА СОВМЕСТНОГО ОТНОСИТЕЛЬНОГО МАНИПУЛИРОВАНИЯ НА ОСНОВЕ ДЕЛЬТА-РОБОТА
}

\section{PARAMETRIC SYNTHESIS OF THE MECHANISM OF JOINT RELATIVE MANIPULATION BASED ON A DELTA-ROBOT}

\section{S. Orekhov \\ P. Veisman \\ G. Mosolov \\ M. Lebed \\ V. Sakharov}

Summary. The purpose of this work is to solve the problem of parametric synthesis of a joint relative manipulation mechanism based on a delta robot. The paper investigates the efficiency of the applied algorithm for selecting the parameters of the mechanism and visualizes its operation.

Keywords: joint relative manipulation mechanism, MSOM, delta robot, mechanism working area, parametric synthesis.

\section{Ввемение}

Д ельта-роботы получили широкое применение в современной промышленности. Они используются для обработки заготовок, сварки, перемещения объектов на конвейере, а также лазерной резке. Для расширения функциональности мехатронных систем данного типа может быть применена концепция механизма совместного относительного манипулирования, которая подразумевает работу двух независимых механизмов, совместно выполняющих одну задачу [1].

Механизмы подобного типа могут применяться для задач различного масштаба: от работы с незначительными объектами, вроде пайки крошечных элементов, до применения в обработке колоссальных объектов, таких как трёхмерная печать деталей для ракет. Такой разброс по размерам объектов применения приводит к проблеме масштабируемости используемых станков. При необходимости оперативной подстройки параметров механизма, при которых его рабочая зона сможет
Орехов Сергей Юрьевич

Старший преподаватель, МГТУ им Н.Э. Баумана

serg31057@mail.ru

Вейсман Павел Игоревич МГТУ им Н.Э. Баумана wepal@mail.ru

Мосолов Григорий Викторович МГТУ им Н.Э. Баумана Grigory2012@bk.ru

Лебедь Максим Дмитриевич МГТУ им Н.Э. Баумана maxim.lebed.98@mail.ru

Сахаров Владимир Валентинович Старший преподаватель, МГТУ им Н.Э. Баумана vlad.saharov2011@yandex.ru

Аннотация. Цель данной работы заключается в решении задачи параметрического синтеза механизма совместного относительного манипулирования на основе дельта-робота. В работе исследуется эффективность применяемого алгоритма подбора параметров механизма и производится визуализация его работы.

Ключевые слова: механизм совместного относительного манипулирования, МСОМ, дельта-робот, рабочая зона механизма, параметрический синтез.

полностью покрыть обрабатываемую область, возникает потребность в параметрическом синтезе механизма.

Параметрический синтез - это процесс определения параметров элементов синтезируемого объекта, при которых будут удовлетворены условия технического задания. При параметрическом синтезе определяются именно параметры элементов, так как структура должна быть задана [2].

\section{Описание исследуемого механизма}

В данной статье исследуется МСОМ с пятью степенями свободы на основе дельта-робота (Рис. 1).

Для дальнейшей работы следует определить параметры, которые будут определены в процессе синтеза.

Параметром, отражающим эффективность работы параметрического синтеза является коэффициент перекрытия. Коэффициент перекрытия - величина отноше- 


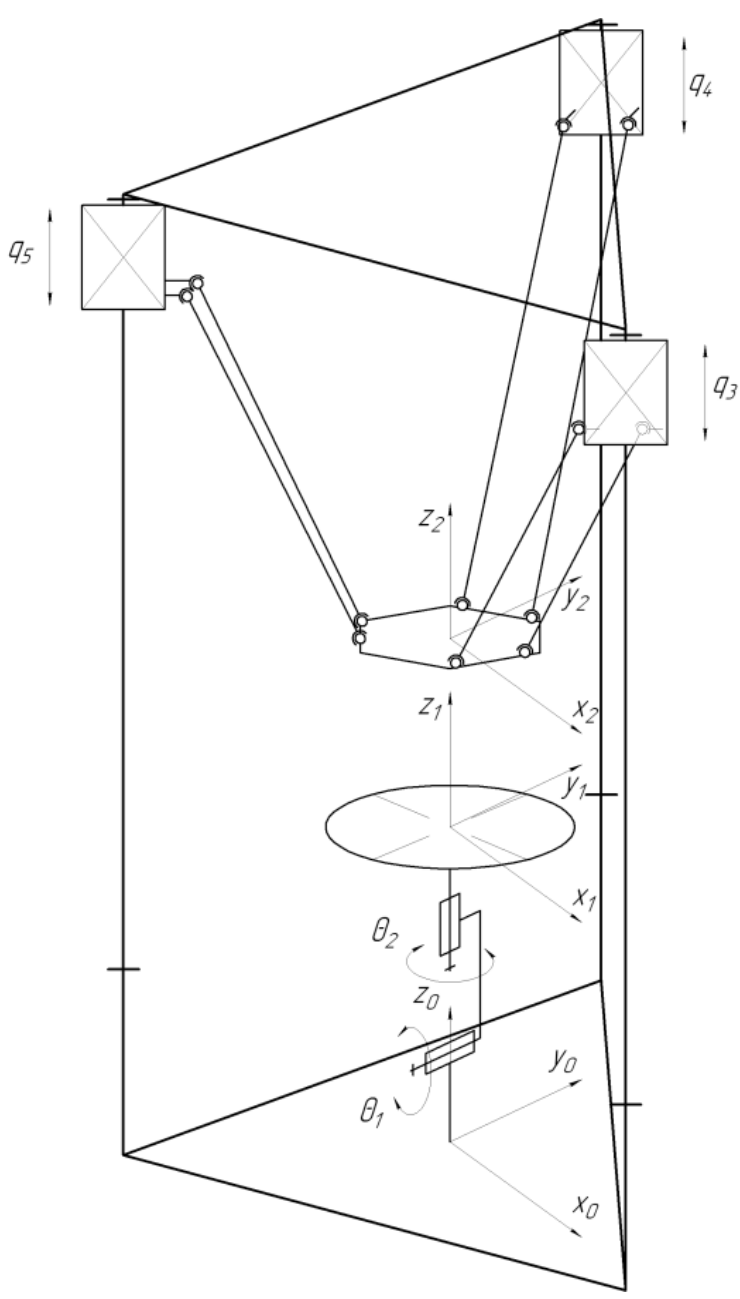

Рис. 1. Кинематическая схема исследуемого механизма

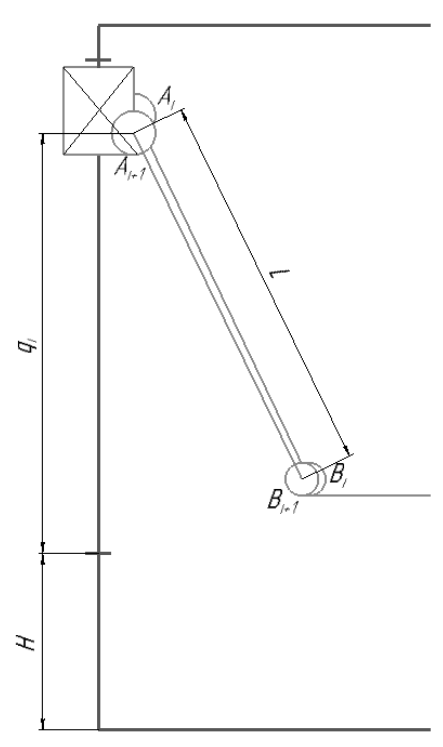

Рис. 3. Высота H

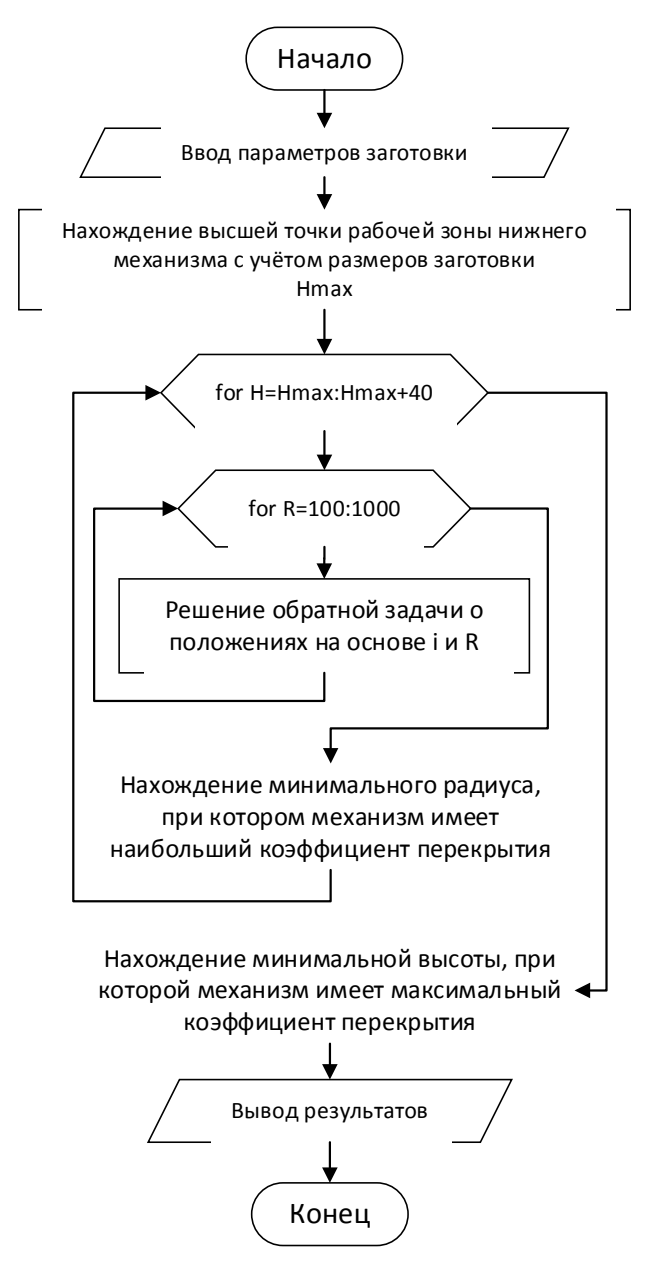

Рис. 2. Блок-схема применяемого в параметрическом синтезе алгоритма

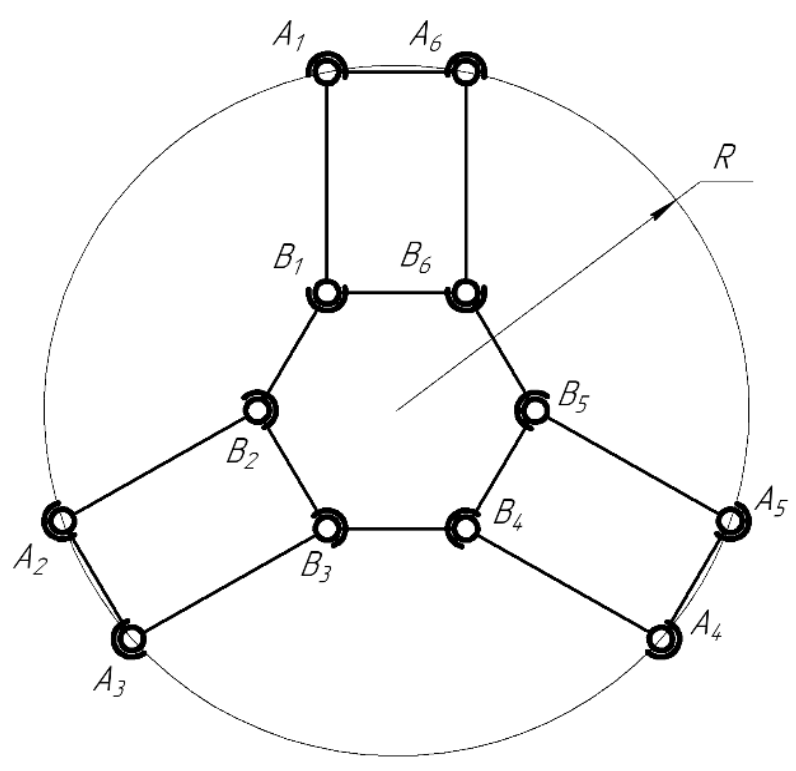

Рис. 4. Радиус R 


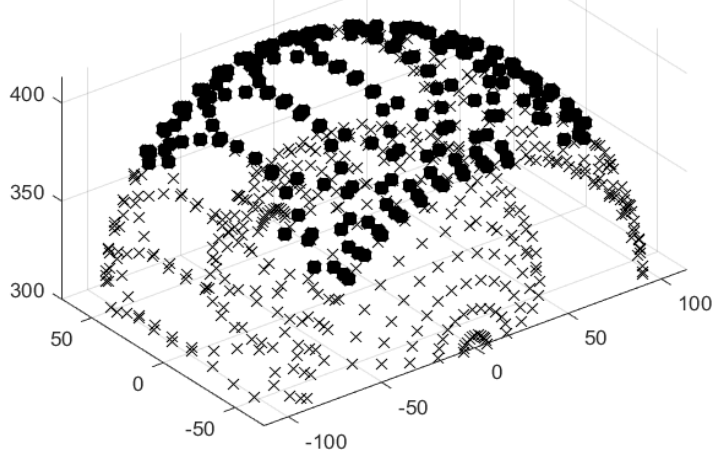

Рис. 5. Коэф. перекрытия 0,7438

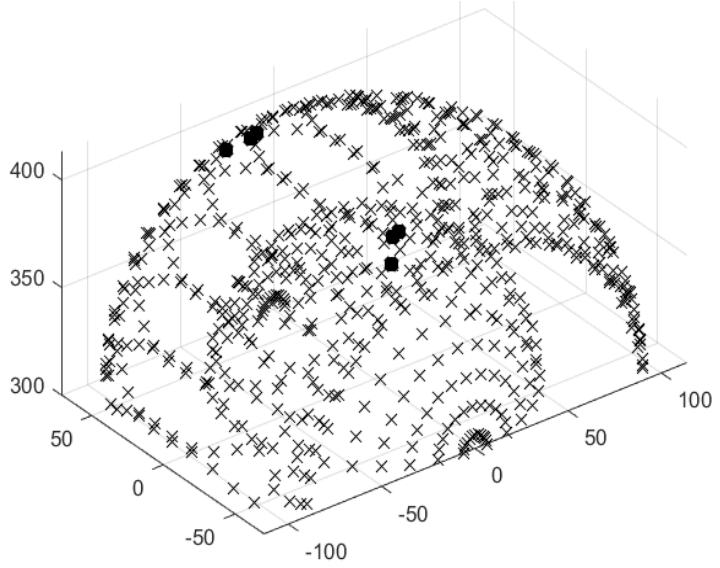

Рис. 7. Коэф. перекрытия 0,9654

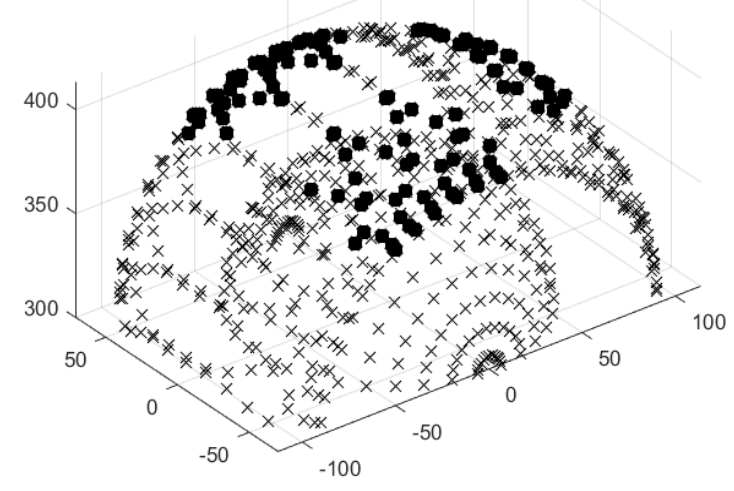

Рис. 6. Коэф. перекрытия 0,8397

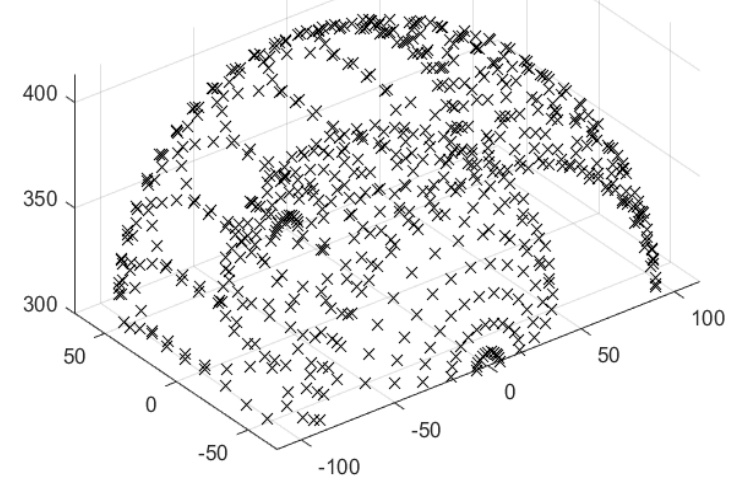

Рис. 8. Коэф. перекрытия 1 ния объёма обрабатываемого объекта, точки которого может достигнуть манипулятор, к общему объёму обрабатываемого объекта, т.е. он отражает, какую долю от общего объёма заготовки может обработать механизм [3].

\section{Описание \\ параметрического синтеза}

В случае механизма, исследуемого в данной работе, синтезируемыми параметрами были выбраны высота расположения линейной направляющей $\mathrm{H}$ (Рис. 3) и радиус окружности $\mathrm{R}$, на которой лежат направляющие, приводящие в движение верхний механизм (Рис. 4).

Таким образом, подобрав правильную комбинацию приведённых выше параметров, возможно добиться максимально возможного для данной конфигурации механизма коэффициента перекрытия (Рис. 5-8).

Успешная конфигурация механизма с заданной структурой предполагает, что коэффициент перекрытия будет максимально возможным в данных условиях, а изменяемые параметры будут минимально возможными.

Для решения такой задачи был разработан общий алгоритм (Рис. 2), показывающий основную идею решения задачи параметрического синтеза для механизма с представленной структурой [4].

\section{Выво $\triangle ы$}

Целью данного исследования является создание алгоритма, позволяющего производить параметрический синтез механизма совместного относительного манипулирования на основе дельта-робота.

Для механизма совместного относительного манипулирования на основе дельта-робота: был произведен параметрический синтез для заготовки с заданными размерами, а также была произведена пошаговая визуализация данного процесса. В будущем планируется оптимизация и унификация данного алгоритма. 


\section{ЛИТЕРАТУРА}

1. Хейло С.В., Глазунов В.А., Ширинкин М.А., Календарев А.В. Возможные применения механизмов параллельной структуры// Проблемы машиностроения и надежности машин. 2013. № 5. С. 19-24.

2. Глазунов В.А., Чунихин А.Ю. Развитие исследований механизмов параллельной структуры // Проблемы машиностроения и надёжности машин. 2014. № 3. C. 37-43.

3. Пащенко В.Н., Власовский А.И., Мясоедов К., Вейсман П.И. Параметрический синтез механизмов совместного относительного манипулирования // Сборник трудов конференции МИКМУС-2018. М.: ИМАШ РАН, 2019. С. 490-493.

4. Зинкевич С.Л., Ющенко А.С. Управление роботами. Основы управления манипуляционными роботами: Учеб. для вузов. М.: Изд-во МГтУ им Н.Э. Баумана, $2000.400 \mathrm{c}$

○ Орехов Сергей Юрьевич ( serg31057@mail.ru ), Вейсман Павел Игоревич (wepal@mail.ru ),

Мосолов Григорий Викторович ( Grigory2012@bk.ru ), Лебедь Максим Дмитриевич ( maxim.lebed.98@mail.ru ),

Сахаров Владимир Валентинович (vlad.saharov2011@yandex.ru ).

Журнал «Современная наука: актуальные проблемы теории и практики»

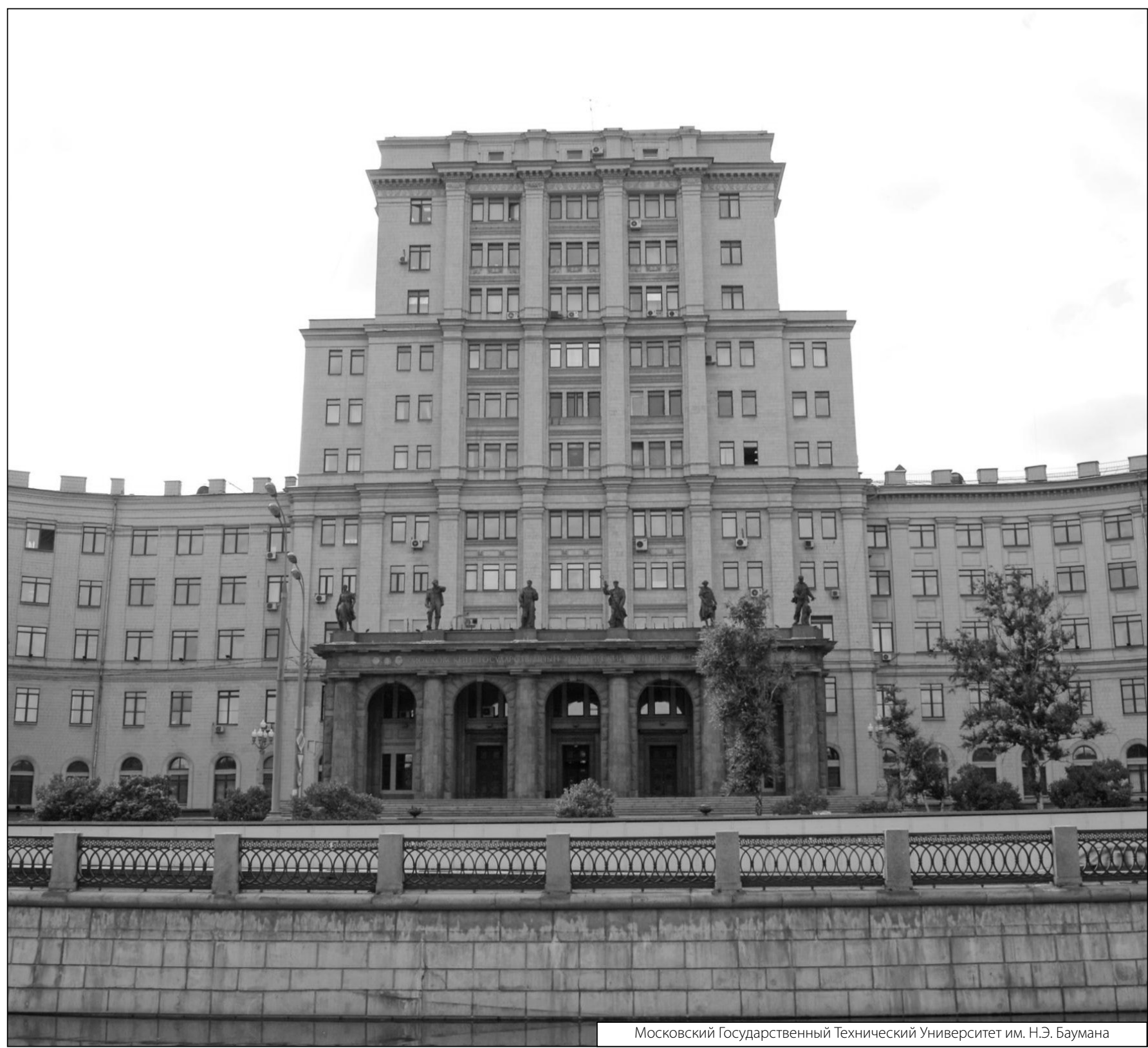

